\title{
Delegation of committee reports in the European Parliament
}

\author{
Fang-Yi Chiou, Silje S. L. Hermansen and Bjørn Høyland
}

\begin{abstract}
Committee coordinators face a classic delegation problem when assigning reports to their committee members. Although few theoretical developments have focused on the effects of expertise on delegation, empirical studies have commonly assumed monotonic effects. Based on existing informational models, we argue that a more loyal committee member, everything else being equal, is more likely to be appointed as a rapporteur and that more expertise, holding preference divergence constant, has a non-monotonic effect because of informational credibility. Employing accumulated committee service as an expertise measure, these theoretical expectations are tested on all committee report delegations in the European Parliament from 1979 - 2014. Our empirical analysis with nonparametric and parametric hierarchical conditional logit models renders strong support for these expectations. The results hold across member states, political groups, procedures, committees, and over time.
\end{abstract}




\section{Introduction}

The European Parliament (EP) is a committee-based legislature dominated by political groups (Whitaker 2001). How to identify, prioritize and allocate legislative proposals to rank-and-file members, who negotiate on their behalf, becomes an essential task for the group's committee leadership. We argue that within-party delegation of legislative tasks follows an informational rationale. The political group needs information about the possible implications of policy proposals that some of its (expert) members can provide. It consequently favors members who have acquired expertise through specialization. However, this does not imply that the members with the most expertise are the most preferred. This is due to informational credibility concerns.

To develop our argument, we first review the literature on committee organization and report allocation in the EP. While there is some consensus regarding the broad empirical patterns, the theories employed for accounting for these patterns apply somewhat inconsistent logics. Building upon extant game-theoretic models developed by Crawford and Sobel (1982) and Fischer and Stocken (2001), we present an informational account of report delegation within political group committee delegations. We highlight the nuanced effects of loyalty and expertise on the probability that a committee member is appointed as a rapporteur, i.e., a committee member assigned with the task of drafting a committee report on the behalf of the committee. While existing political science studies have conventionally asserted that the principal is monotonically more likely to appoint an agent with more expertise to pursue policy on the former's behalf, Fischer and Stocken (2001) theoretically demonstrate that this expectation falls short of a theoretical foundation.

Another contribution of this article is the granularity of our data. While existing research tests allocations at an aggregated level, e.g. the number of reports per term (e.g. Yoshinaka, McElroy and Bowler 2010), we consider only the alternatives that the committee-coordinator can realistically choose between. At each allocation the coordinator can only select amongst committee members from the same political group. We call this his 'choice-set'. We then calculate the variables to reflect the information available to 
the coordinator at the time of the decision. For example, our loyalty score relies only on votes cast up to the time of the decision, rather than averaging over whole time-periods. Similarly, committee-specific policy expertise is not measured in terms of binary categories such as incumbent or freshman, but as days spent on the committee until the day of the report delegation.

Across nonparametric and parametric conditional logit models, we find a linear effect of loyalty and a non-monotonic effect of committee-specific policy expertise on the probability of being delegated a report. While the coordinator initially prefers expertise, growing expertise may not generate a strictly positive returns. This nuanced effect is consistent across member states, committees, political groups, procedures, and over time.

\section{Rapporteurs in the EP}

The rapporteur collects information and negotiates a consensus within the committee. Later, she defends the committee compromise during the plenary reading, and continues to follow the dossier during inter-institutional bargaining. On the one hand, the rapporteur must identify a suitable coalition within Parliament. The rapporteur must decide if a super-majority is needed to promote Parliament's institutional interests or if partypolitical contestation is called for (Hix, Kreppel and Noury 2003; Hix, Noury and Roland 2005; Kreppel 2000; Hagemann and Høyland 2010). On the other hand, the legislative outcome depends on agreement with the Council and support from the Commission. The rapporteur must therefore identify interests represented in the other institutions particularly on her or his committee's policy areas and form proposals that the majority in those institutions is willing to accept (Costello and Thomson 2010). Roger and Winzen (2015), building upon Ringe (2010), emphasize the importance of coalition-building within committees as well selective involvement of the political groups more broadly (see also Benedetto 2005). In matters pertaining to particular proposals, the rapporteur is therefore the most influential Member of Parliament (MEP), and its success depends on her political skills.

The rapporteur is center-stage in Parliament's committee system. Bowler and Farrell 
(1995) discuss to what extent standard legislative theories can shed light on organization in the EP (for an overview of these theories, see Martin 2014). Their study informs subsequent work on committee assignments in the EP (Whitaker 2001; Mamadouh and Raunio 2003; McElroy 2006; Yordanova 2009, 2011a; Whitaker 2011; Chiru forthcoming). The same framework has often been used to understand individual assignments such as rapporteurships (Kaeding 2004; Benedetto 2005; Yoshinaka, McElroy and Bowler 2010; Hurka and Kaeding 2012; Yordanova 2011b; Daniel 2013; Hermansen 2018), shadow rapporteurships (Hurka, Kaeding and Obholzer 2015) as well as the group leaders themselves (Daniel and Thierse 2018). Many of these studies find that participation, voting loyalty, relevant extra-parliamentary experience as well as time on a committee are important predictors of an appointment (see also Ringe 2010). Moreover, partisan and informational theories are considered to provide the better fit as loyalty and expertise consistently increase the probability of delegation (Whitaker 2001; Kaeding 2004; Yoshinaka, McElroy and Bowler 2010; Daniel 2013). Of particular relevance here is the work on the selection of party group coordinators. Daniel and Thierse (2018) find that MEPs who are appointed committee coordinators possess policy expertise in the form of committee incumbency and relevant professional background. Moreover, Obholzer, Hurka and Kaeding (2019) show that these coordinators tend to select rapporteurs that are closely aligned with their own policy positions.

However, frameworks developed to understand collective committee assignments can neither accurately describe individual report allocations nor provide theoretical foundation for what shapes them. Gilligan and Krehbiel (1987) develop their informational approach based on the presumption that the floor can induce committees to share information by pre-committing to closed rules for amendments. While Gilligan and Krehbiel (1987) focus on the floor's ability to monitor and sanction committees, we argue that report allocation is essentially a question of selection within political groups that act as gatekeepers with few means of monitoring and that seek a reliable and capable agent. In short, the transmission of information from rapporteurs to the political group should be thought of separately, and differently, from what is conceived in the traditional literature 
on committee assignments. As is the case for the partisan approach, we consider withingroup cooperation. However, our explanation for the enforcement of loyalty is grounded in an informational argument.

\section{An informational account of report allocation within political}

\section{groups}

In the partisan approach, leaders sanction unruly members by removing them from, or not promoting them to, salient positions. Members accept the discipline for a series of reasons that are not present in the EP. In contrast, we argue that - because of their relatively weak position - groups select policy-makers that, by and large, pursue preferences shared by a majority of their members. This also reduces the need for disciplinary measures later in the process.

Our approach generates new empirical implications that have not yet been tested. We consider selection as a function of the rapporteur's incentives for policy drift (i.e. preferences) and his capacity to induce such a drift (i.e. specialization).

The committee coordinator is the principal. The rapporteur is the agent whose role is to provide information. A coordinator acts on the rapporteur's initiatives. Proposals are discussed and voting instructions are issued in group meetings before the plenary deliberation. The report can also be amended on the coordinator's initiative both in the committee and in the plenary. When acting, the coordinator must rely on information transmitted from the rapporteur. Whether the rapporteur is willing to truthfully transmit as much information as possible becomes a crucial factor in the appointment decisions.

The cheap-talk game of Crawford and Sobel (1982) corresponds well to the strategic interaction between political group leaders and their appointed rapporteurs. The game they develop has two players with different preferences. The agent (typically called a 'sender') will submit a report to the principal (called a 'receiver') containing a certain amount of information, followed by the receiver's move to make a final policy. Crawford and Sobel argue that, as long as preference divergence is not too large, the sender with preferences more in line with the receiver's reveals more information, since this leads the 
principal to take actions close to what the agent would like. Based on their theoretical results, we expect leaders to select rapporteurs with similar political preferences to the group majority. They learn about these preferences by observing members' voting loyalty.

H1: A coordinator is more likely to appoint a member with higher voting loyalty.

Another critical component in informational theory is specialization. The importance of expertise in the EP has generally been justified by reasoning that a more specialized agent can transmit more information. Authors often cite Krehbiel (1991) as source for this intuition, which hypothesizes that a more specialized committee is more likely to receive a restrictive rule for amendments and that a more specialized congressman is more likely to be appointed as a conference committee member pursuing policy outcomes on behalf of her or his chamber. However, in the models, the sender is assumed to be either specialized or non-specialized. Understanding the effects of expertise on informational transmission requires modelling expertise as a continuous variable, which has not yet been explored in political science, as far as we know.

Taking preference divergence for granted, Fischer and Stocken (2001) theoretically examine the relationship between the sender's quality of information and the information she reveals. When the sender does not have any information about the policy uncertainty of the receiver, the sender's signal contains no useful information and both of the players suffer from policy uncertainties. However, once the sender starts to specialize, information is weakly preferred to be transmitted to the receiver because better information can help the latter sort out uncertainties and adopt a final policy beneficial to both of them. This implies that the receiver may initially prefer a more specialized sender.

However, Fischer and Stocken (2001) find that, as the sender acquires more expertise, everything else being equal, the two players may run into conflict, undermining information transmission. With preference divergence fixed, increasing expertise has direct and indirect effects on the quality of the information transmitted. The direct effect is that the sender has more information and is therefore capable of revealing more information to the receiver. The indirect effect is that increasing expertise would eventually undercut the credibility of the signal. Suppose that the sender prefers the receiver to take a higher 
action than would be taken if both had the same information. Increasing from no private information to coarse information, the direct effect would dominate the indirect one, because it is Pareto optimal for the sender to reveal coarse information so that the receiver would take different levels of action conditioning upon the signal. With more and more specialization, the receiver would be concerned about whether the sender, who now has more leverage to choose signals, may send misleading signals to trick the former to take a higher action. This means that the indirect effect may dominate the direct one when the sender is very specialized. If information collection is the most critical factor in coordinator's rapporteur appointments, the consequence is that expertise has non-monotonic effects, holding preference divergence constant.

H2: A coordinator is more likely to appoint a member with a higher level of expertise, but the effect is non-monotonic.

Note that Fischer and Stocken's (2001) model only implies that the effect of expertise is non-monotonic. It does not suggest that the effect would have a particular non-monotonic pattern, such as an inverted U-shaped relationship. Furthermore, their results neither suggest whether nor how the effect of expertise depends on the extent of misaligned incentives. We speculate that it should depend on the utility functions of the sender and the receiver as well as the nature of the sender's private information system. To empirically examine the interactive effect, we will include the interaction term between loyalty and expertise.

Our theoretical approach goes beyond what has been proposed or discussed in the literature. In line with previous research, we expect that loyalty and expertise are important criteria when parties select their policy makers. However, by focusing on the rapporteur as a provider of information, we outline a coherent theoretical framework for these two hypotheses and make predictions about when these criteria apply and why.

\section{Data, measurement, and statistical models}

We have collected data on all reports allocated to individual committee members from the beginning of the $1^{\text {st }}$ directly elected EP in 1979 until the last meeting of the $7^{\text {th }} \mathrm{EP}$ 
in 2014. The data were gathered from the Official Journal of the European Union and the EP webpages. Reports without rapporteur and reports where the group had only one member in the committee at the time are excluded, as no meaningful delegation is possible. This has left us with 11,075 delegation decisions.

For each report, we identified the rapporteur, the main committee, and the political group responsible. We generated the relevant membership of the political group delegation to the committee using data from Høyland, Sircar and Hix (2009). These sets of political group committee members form the basis for the group leadership's choice of rapporteur. We label them 'choice-sets'. These choice-sets consist of all full committee members belonging to the political group. It is from within this set that the group coordinator can pick the rapporteur. To create these choice-sets, we used the date of the adoption of the report in the plenary. Here, we rely on the assumption that the coordinator would not seriously consider members who were planning to leave the committee prior to the presentation of the report to the plenary. The substantive results are the same. These choice-sets vary in size across committees, political groups and over time.

Our focus is on the relative effects of loyalty and expertise on the likelihood of being selected as rapporteur conditional on being a member of the choice-set. In other words, conditional upon being in charge of a report, we model to whom amongst its committee members the political group coordinator grants the task of writing the committee report.

\section{Voting loyalty}

We need a measure that approximates the information available to the coordinator at the time of allocating the report. Newcomers and coordinators have little to no knowledge of each other prior to their entry to the Parliament, since they usually do not share national party affiliation. We therefore assume that coordinators learn about members' preferences through their parliamentary activities, notably their voting behavior. Observing higher levels of voting loyalty suggests to the committee leadership that the Member of the European Parliament (MEP) has more similar preferences than members with lower scores. Although observed roll-call votes or loyalty scores likely reflect preferences induced by 
party pressure, they can nevertheless reveal the MEP's loyalty relative to other MEPs.

Our calculation of loyalty is as follows. For each vote, we identify the majority position of the group. Then, for each MEP, we code as 1 if the vote is cast with the majority, and 0 if it is against. We sum this across all votes up until the date of the allocation. We then divide this number $(+1)$ by the total number of votes $(+1)$ in which the MEP has participated up until the decision date. This score is calculated for each MEP at each choice-set. ${ }^{1}$

One concern regarding this operationalization is the informative value of roll-call votes as a measure of loyalty. Individual votes are not consistently recorded in the EP. Indeed, roll-call requests vary between groups, across topics and by procedures (Carrubba et al. 2006). A key concern is that behavior during these votes may be different from behavior in other (non-recored) votes, potentially biasing statistical inference about true preferences. There is a lively, and unresolved, debate regarding the extent of this bias (Yordanova and Mühlböck 2015; Hug 2016; Hix, Noury and Roland 2018), as well as the empirical pattern of roll call requests (Finke 2015; Thierse 2016). However, our assumption is that the group leadership faces the same bias in the recording of roll-call votes as researchers do, and simply rely on what is available to them.

\section{Expertise}

Expertise is central in any informational account of report allocation, but the concept is contested and elusive. The literature has considered several different measures of expertise. To some, expertise is about what you bring in to the Parliament, in particular in the form of work experience (Yoshinaka, McElroy and Bowler 2010; Yordanova 2011b) or from national policy making (Hermansen 2018). To others, the key aspect is more broadly captured by members' level of education (Daniel 2013). These approaches allow expertise to be highly policy-specific. A farmer brings with him expertise that may be relevant in to policy-making in the agriculture committee, but not to the foreign affairs

\footnotetext{
${ }^{1}$ If there is no voting record for an MEP at a particular choice-set, or if there has yet to be a roll-call vote in the parliamentary session, we replace the missing information with a random number between 0 and 1 to reflect the coordinators uncertainty.
} 
committee. In contrast, a lawyer might have relevant expertise not only on the legal affairs committee, but on all regulatory committees. However, this is also a relatively crude classification, as the educational and professional background may have provided them with a set of skills that differ substantively from the skills that are necessary for policy makers on a committee. Furthermore, common to these approaches is their focus on what MEPs brought with them when entering office. As a result, it is a static and often binary measure of expertise. It is binary in the sense that an MEP either has expertise or not. ${ }^{2}$ It is static in the sense that an MEP lacking expertise when entering the EP will not develop it during her time in office. This is particularly problematic for the number of career politicians who make their debuts at the European level. This is not to say that MEPs' background is not useful during delegation decisions. In the model, we therefore capture such effects with individual committee-specific intercepts, as detailed below.

As an alternative to policy-relevant expertise, we rely on committee seniority. It is defined as the number of years a legislator has served on a committee across terms and has been widely adopted in the literature on legislative studies (McConachie 1898; Luce 1922; Clapp 1963; Huckshorn 1965; Buchanan et al. 1970; Schneier 1970; Tobin 1986; Krehbiel 1991). A legislator staying on a given committee longer is more likely to frequently join committee meetings and develop more policy expertise for this committee. While having higher education or related professional work experience can be helpful in boosting learning, it is also a broad and possibly unspecific approximation for knowledge about a committee's policy jurisdiction. By contrast, staying on the same committee is a more direct approach to specialization in relevant policies. As Krehbiel (1991, 171) pointed out, there is 'a huge literature on state and national legislatures that provides strong empirical support for the relationship between committee service and policy expertise'. His seminal work on informational theories employed this measure of expertise in examining competing theories of legislative organization in United States Congress and testing the effects of expertise on the probability of being appointed as a member for conference committees where the two chambers negotiates for a bill. While Krehbiel counts

\footnotetext{
${ }^{2}$ To be more precise, Daniel (2013) has four categories of education to code an MEP's highest degree.
} 
the length of a legislator's consecutive committee service over time, our definition of committee seniority is more inclusive than his, as we count any previous committee service for a given committee. This makes better sense in the context of EP for two reasons. It is not uncommon for an MEP to switch committees. Some MEPs left the EP for some time (e.g. taking up a seat in the national parliament for a while) and returned to the same committee later on. Our study is similar to Krehbiel (1991) in that we are examining the role of committee-specific expertise in legislative organization and, specifically, its effects on the probability that a legislator is delegated to pursue policy goals on behalf of her committee.

Following Krehbiel (1991), we use committee seniority to measure committee-specific expertise and count the years of being on a committee up to the day of this committee's rapporteur appointment. This measure has also been used in the EP context. Daniel and Thierse (2018) rely on a similar measure of committee - experience when studying selection of group coordinators. In explaining report assignments, Yoshinaka, McElroy and Bowler (2010) included a linear control for the length of an MEP's committee service within a term. The variable captures a shorter period of time and was included not to capture expertise. Instead, they opt to employ previous careers and EP seniority as their two alternative measures of expertise. Obholzer, Hurka and Kaeding $(2019,250)$ use count of half-terms to measure committee experience. In line with our logic, they see it as a measure of 'specialization [that] could be rewarded by more reports'. A unique feature of our operationalization is the granularity of our measure. The updating process accounts for an MEP's developing expertise within a term. This allows us to distinguish between different levels of expertise among MEPs who joined with similar background. It allows us to distinguish committee seniority from EP seniority as we account for committee switching.

\section{Control variables}

As a measure of general parliamentary experience, we use chamber seniority which counts the number of years serving in Parliament up to the time of report allocation. As Krehbiel 
(1991) argued, this measure captures legislative experience independent of the committee's jurisdiction and is not suitable for capturing committee-specific expertise. Committee and EP seniority are certainly highly correlated. An MEP staying longer on a given EP committee has higher EP seniority, but not necessarily the other way around. For our theoretical interests, committee-specific expertise is more relevant and precise than general experience. However, chamber seniority controls for the policy-irrelevant 'learning on the job' which could confound the effects of committee-specific expertise. In the remainder of the article, we use expertise to denote committee seniority and employ seniority to denote EP seniority. We rely on Høyland, Sircar and Hix (2009) for the data of these variables.

A central control variable in the literature on the EP has been legislative participation (e.g. Yoshinaka, McElroy and Bowler 2010; Hurka and Kaeding 2012). The consensus is that a more active MEP is more likely to be appointed as rapporteur, either as a reward for past service or as a self-selection into legislative tasks (e.g. Benedetto 2005). Just as loyalty, participation is calculated on the basis of data from roll-call votes, dividing the number of votes participated in by the number of total votes that have been cast in a given term until the decision date. ${ }^{3}$

The non-monotonic effects of expertise may be driven by members who reduce their activity towards the end of their career. This may be because of age (Meserve, Pemstien and Bernhard 2009; Bailer and Ohmura 2018) or a de facto early retirement (Daniel and Metzger 2018). Career-oriented members also frequently shift focus to other relevant arenas for the next stage in their career (Høyland, Hobolt and Hix 2019). The models therefore control for age and its squared term as well as an indicator for reports allocated during the MEP's final year.

Many MEPs switch party or political group affiliations (Hix and Noury 2018). To account for the possibility that political group switchers were rewarded by their new groups through report allocation, we include a dummy-variable for party switchers. Like previous studies, we also control for leadership roles in the national delegation and the

\footnotetext{
${ }^{3}$ For an exception, see Hermansen (2018) who relies on participation in committee meetings. Unfortunately, data on participation in committee votes are not available for the whole period covered in this study.
} 
group. We flag as leadership positions all trusted positions, leaving only rank-and-file members as non-leaders. Committee chairs and vice-chairs are, for their part, coded as committee leadership. Last, we account for for MEPs with leadership-roles in the Parliament. The Online appendix provides the descriptive statistics for our variables.

\section{Statistical model}

Existing literature has relied upon logit and count models to capture factors that determine whether an MEP writes at least one report during a specific time frame, or alternately how many reports an MEP drafts during a specific time frame. As we are interested in the decision of who is appointed as a rapporteur conditional upon the political group obtaining the responsibility for a report, our statistical approach is different. Thus, we use conditional logit models to realistically describe aspects of the group's committee members that may affect the coordinator's choice. We therefore do not estimate the probability of the outcome of interest given the values on the covariates, but rather how covariates affect the relative probability of one member in the choice-set being selected over the other alternatives. Within each choice-set the sum of the probabilities across units is one, so there is no baseline intercept in these models.

Our theoretical focus is on within-group allocation of reports and the conditional model explicitly describes that dynamic. However, this also means that choice-set level control variables that describe how selection criteria vary between groups can only be included as interaction effects in a mixed conditional logit. We have not theorized these effects and therefore drop previously included controls aiming at explaining such differences in the main models. However, to ensure that our findings are not driven by idiosyncrasies, we nevertheless explore if elements such as political groups, committees, procedures, timeperiods and nationality condition the findings. These elements are included primarily as random intercepts but we also explore their conditional effects through random slopes. Our choice is detailed below. Since most of the existing literature has looked at the determinants of the number of reports drafted by each MEP - including contextual variables - conflicting results may arise from the difference in design. 
We rely on hierarchical modeling because individuals are observed several times. As members may serve on multiple committees simultaneously or over time, we use committee specific MEP intercepts. A couple of members have furthermore been elected from different member states in different periods. For these MEPs, we include one set of such intercepts per country that they have represented. This allows us to capture individual aspects that affect their probability of being selected. Existing literature has highlighted several such factors, including work experience, education, and ties with interest groups (Daniel 2013; Yoshinaka, McElroy and Bowler 2010). MEPs may have other, unforeseen characteristics that affect their suitability as rapporteur. However, as the MEP intercepts are committee specific, they allow for the importance of these factors to vary across committees. Mamadouh and Raunio (2003) argue that country specific cultural factors influence report allocation. Moreover, some national party delegations may need time to learn how the EP operates and properly adjust (Lindstädt, Slapin and Wielen 2012). Hence, we nest the MEP-committee specific intercepts within countries. This allows us to account for time-invariant policy-specific expertise of MEPs as well as country specific differences.

These effects are estimated using Bayesian hierarchical conditional logit models (Gelman et al. 2014) provided by the rstanarm library (Stan 2016) in R-3.5.1 (2018). To ensure that results are not driven by outliers, we use $t$-distributions with 7 degrees of freedom (Gelman et al. 2014). Starting values were generated using frequentist conditional logit models without random MEP intercepts. We then added random noise to these by drawing from normal distributions with the frequentist estimate as mean and a standard deviation of .1. We assign default prior on the covariance. ${ }^{4}$

In subsequent models we first allow the slope to vary by country. Then, we allow the slope to vary by political group, committee, procedure, or over time. As these latter groupings do not vary within each choice-set, we only vary the slopes of the variables by grouping levels. These slopes will capture to what extent the variables of theoretical

\footnotetext{
${ }^{4}$ We follow the recommendation from the Stan (2016) documentation, setting decov(regularization $=1$, concentration $=1$, shape $=1$, scale $=1$ ). We ran 5000 iterations on four chains, discarding the first 2500 iterations on all chains.
} 
interests differ by grouping level. This approach provides direct tests of differences in the selection criteria across political groups, committees, procedures, and over time.

We begin with a preliminary exploration of the data. In a parametric setting, model results may be driven by the choice of priors or of the exact specification of the functional form of the relationship or the inclusion or exclusion of interactions. To guard against such concerns we first employed a new machine-learning approach called 'boosting conditional logit model' (Shi and Yin 2018). The approach implements component-wise smoothing spline to estimate covariate effects non-parametrically. The boosting procedure has been shown not to be prone to overfitting and has the ability to capture potential nonlinear effects. Any nonlinear effect captured by this estimation procedure cannot be explained away by the researchers' particular choice of functional form as the approach is nonparametric. In the results section, we first present these non-parametric results to establish the functional form of the relationship, before estimating the parametric models.

\section{Results}

Figure 1 presents the marginal results from the boosting conditional logit model. These results show that there is a positive marginal effect of loyalty on the chance of being selected as rapporteur. As such, a high level of loyalty is almost a prerequisite for being considered seriously as rapporteur. There is no strong evidence for an inverted U-shaped relationship between loyalty and the probability of being selected.

For expertise, in contrast, the relationship is non-monotonic. MEPs in their first term are at a disadvantage. With more than one term worth of relevant committee experience, the marginal effect is generally positive but it increases at a decreasing rate until it reaches its maximum after 17.5 years. Additional committee expertise is a liability rather than an advantage. MEPs with more than 22.5 years in the same committee are less likely to be selected than MEPs with 5 years worth of committee expertise. In other words, the effect of committee expertise is clearly non-monotonic. Additional expertise is a clear advantage for the vast majority of members as their stint within the same committee last shorter than 17.5 years. However, those MEPs that stay longer than that in one 

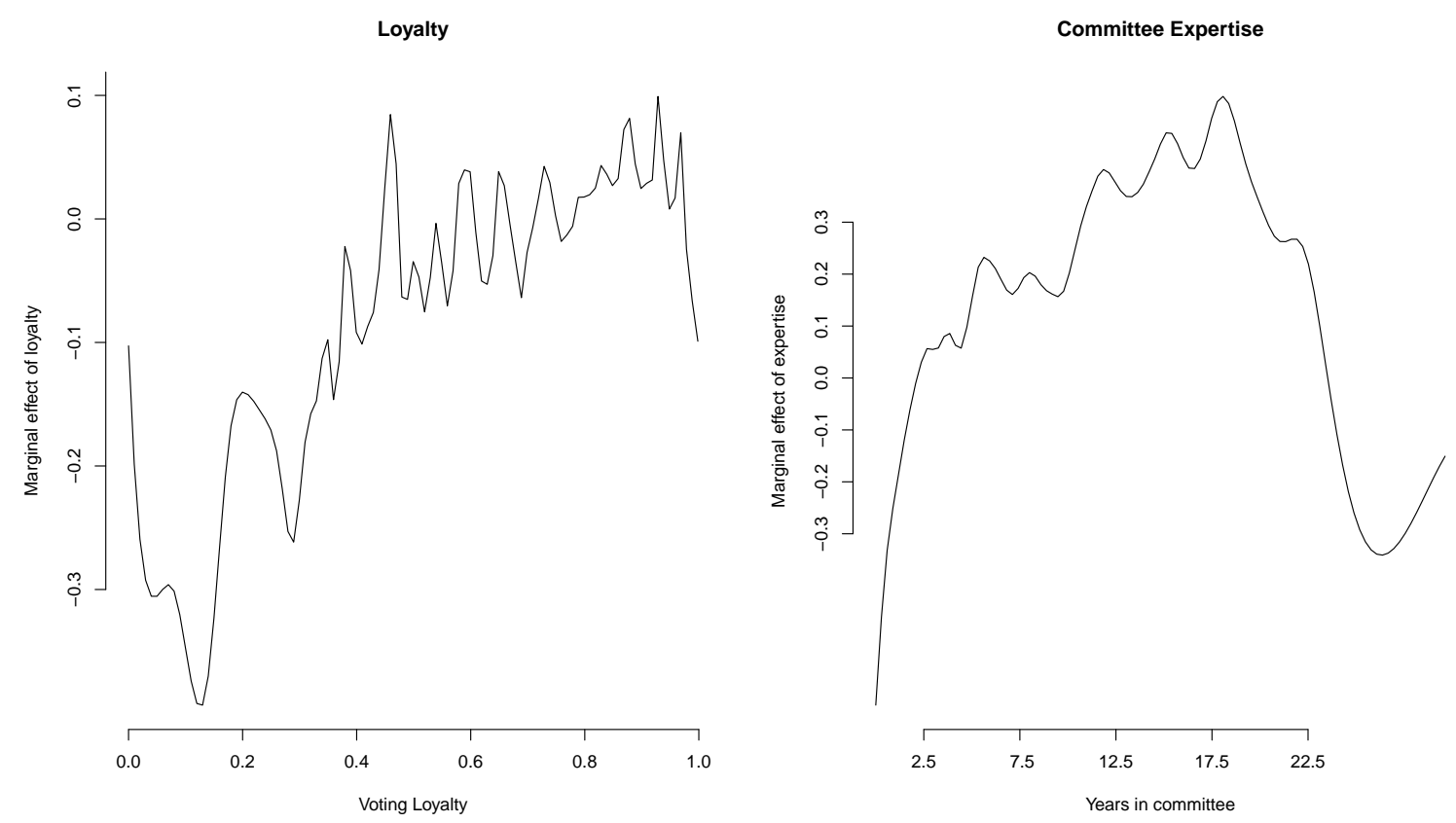

Figure 1: Boosting conditional logit models. These figures show the marginal effects of loyalty (left) and expertise (right).

committee are at an increasing disadvantage when reports are allocated. While we have established that the relationship is non-monotonic, the magnitude of the effect and the exact turning-point should be taken with a grain of salt as this model does not take MEP specific effects into account. Moreover, this non-parametric model does not provide reliable uncertainty estimates. Hence, we move on to parametric models.

Table 1 presents the main results from the hierarchical conditional logit models. Model 1a includes only the variables of theoretical interest: loyalty, expertise, expertise squared and the interaction between these. The control variables are then added in Model 1b. Both models include random committee-specific MEP intercepts nested in countries. These intercepts take personal characteristics into account. The MEP-specific intercepts have country-specific means, modeled as county-specific intercepts drawn from a normal distribution with a mean of zero. This allows us to measure and account for unobserved country-specific differences in the probability of being selected to write a report.

The key message from Table 1 is that the results are in line with our theoretical expectations. Moreover, the results are not sensitive to the inclusion of the control variables. The coefficients of loyalty and expertise are positive and of substantial magnitude. An 
MEP with a loyalty score of .95 is $67 \%$ more likely to be selected as a rapporteur than one with a score of $.5 .^{5}$ The coefficients of expertise and expertise squared are positive and negative, respectively. Moreover, both are statistically significant. This indicates an inverse U-shaped effect of expertise. The coefficient for the interaction term between loyalty and expertise is negative and statistically significant, but this result does not hold under different operationalizations of loyalty, as detailed in our Online appendix. Furthermore, while the coefficient of the interaction between loyalty and expertise squared is positive, the magnitude is not substantively larger than the standard error.

Based on Model 1a, we illustrate the effects of expertise. ${ }^{6}$ Figure 2 demonstrates the effects of expertise on the estimated probability conditioning on different levels of loyalty. For MEPs at the start of their career, there is a substantive positive relationship between expertise and probability of being allocated reports. The inverted U-shaped curve furthermore persists under different levels of loyalty. Comparing the height of the estimated effect on the far left of each of the subplots, we see that the curve starts higher up on the y-axis and has less steep slope as we move to subplots conditioned on higher levels of voting loyalty. This means that an MEP with lower loyalty scores can improve the probability of being selected as a rapporteur more substantially from no expertise to 10 years of committee expertise, but this is not the case for the next 10 years. Among very loyal MEPs, the probability is generally higher and the curvature of the effect slightly less pronounced. ${ }^{7}$

The effects of the control variables are displayed in Table 1. While EP seniority is negative, the magnitude of the effect is tiny compared to the effect of committee expertise.

\footnotetext{
${ }^{5}$ From Model 1a, we see that the coefficient of Loyalty is 1.137. $\frac{e^{(1.137 * .95)}}{e^{(1.137 * .5)}} \approx 1.668$.

${ }^{6}$ Since the choice-set, i.e. the political group delegation to the committees, varies substantively in size, the effect of a one unit change in a coefficient on the probability of becoming a rapporteur may depend on the size of the choice-set. Here, we fix the choice-set to five MEPs. When illustrating the effects in these figures, we hold the other MEPs at the median level of loyalty and committee experience. Because very few MEPs stay on the same EP committee for more than four terms or have loyalty scores below .5 , we vary loyalty from 0.5 to 1 and restrict committee expertise to range from 0 to 22.5 years. On the basis of these values, we calculate the probability of this member ending up with the report.

${ }^{7}$ As mentioned above, loyalty scores indicate relative loyalty, as observed voting decisions likely reflect party-induced preferences.
} 


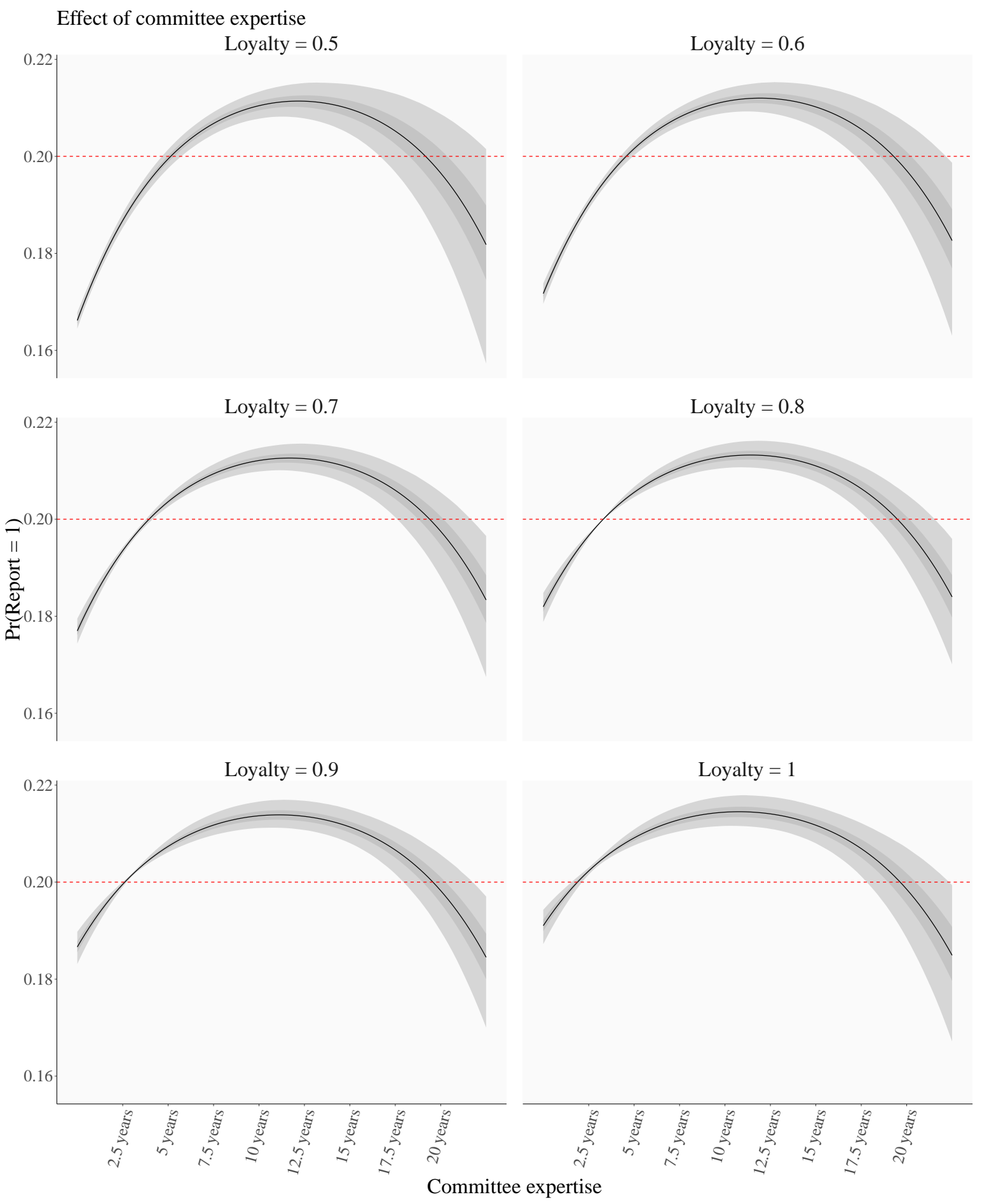

Figure 2: Substantive effect of committee expertise given loyalty.

Based on Model 1a. Size of choice-set is 5. Dark (50\%) and light (95\%) shaded ribbons for credible intervals. 
The coefficient of the squared term of EP seniority is small compared to its standard error. In other words, committee expertise matters a lot more than EP seniority. Age has a positive effect, with a decreasing impact. MEPs in the political group leadership are about $11 \%$ more likely to be selected as rapporteur than ordinary members. This difference is small in comparison to the difference between committee leaders and ordinary members, however. Committee leaders are more than twice as likely to be selected to draft reports, most likely because they are the fallback option in case no other member of the delegation can be convinced to take on the task. In contrast, there is no discernible difference in the probability of writing reports between MEPs in EP leadership roles and ordinary committee members. Nor do we find any clear effect of political group switching. However, we do find that MEPs in their final year are about $21 \%$ less likely to be delegated reports.

\section{Varying coefficients by groups}

In this subsection, we test to what extent the key findings hold across different categories of MEPs. As our models are hierarchical, we do this in a principled manner by letting all of the variables of theoretical interest vary across different subgroups. We consider five different grouping levels; member states, political groups, committees, procedures, and time periods.

First, in Model 1c, shown in the Online appendix, we let the coefficients vary by member states. Mamadouh and Raunio (2003) found differences in allocation pattern across member states and attributed these to differences in language skills and culture. This model is a straightforward extension of Model 1a, only with varying slopes as well as intercepts at the country level.

As shown in the appendix, our main results hold across all member states. They are not driven by any particular member state, with only minor differences across nationalities. In line with Mamadouh and Raunio (2003), we find, for example, that MEPs from the Netherlands are more likely to be selected than what loyalty and committee expertise alone can account for. In the case of the Czech Republic, we cannot definitely say that 
loyalty is positive. For Belgium, France, Germany, Italy, Malta, the Netherlands, Slovenia, Spain, and the United Kingdom we can conclusively state that the interaction between committee expertise and loyalty is negative. However, while there is a clear positive tendency in the interaction between committee expertise squared and loyalty, the effect is not statistically different from zero for any particular country. The overall picture is that the results hold across member states and that the country differences are minor.

Second, Model 1d, illustrated in the Online appendix, allows coefficients to vary across political groups. Given that each choice-set only considers committee members from the same political group, we do not estimate group-specific intercepts, but the slopes of the coefficients from Model 1a vary for each political groups. To control for idiosyncrasies, the model further includes committee-member and national-specific intercepts. The key finding here is that there is little variation in the coordinators' selection criteria across groups. In other words, the results are neither driven by a handful of political groups, nor is it the case that some groups are exempt from the logic.

Third, Model 1e allows the coefficients to vary by committees. Again the pattern is stable, but the effect of loyalty is somewhat stronger in the budgetary control committee $(\mathrm{CONT})$ than elsewhere. We also see some heterogeneity in the squared term of expertise. While the effect is always negative, it is stronger in the Foreign Affairs (AFET) and Budgetary Control (CONT) committees, and smaller in the Budget (BUDG), Economic (ECON), and Industry, Research and Energy (ITRE) committees. These findings suggest that the second-order effect of expertise is most pronounced in CONT.

Fourth, Model 1f allows the coefficients to vary by procedure. The procedure-specific estimates are summarized in the online appendix. We see that the findings are consistent across all procedures. In other words, there is nothing to suggest that our theoretical logic only applies to a subset of Parliament's major legislative procedures.

Fifth and finally, Model $1 \mathrm{~g}$ lets the coefficients vary over time. Again, the main pattern is stable across terms. However, the coefficient estimates vary somewhat over time. Loyalty is trending upwards. Low voting loyalty is increasingly a liability for MEPs seeking rapporteurships. This should be seen against the gradual increase in voting loyalty 
Effect of committee expertise
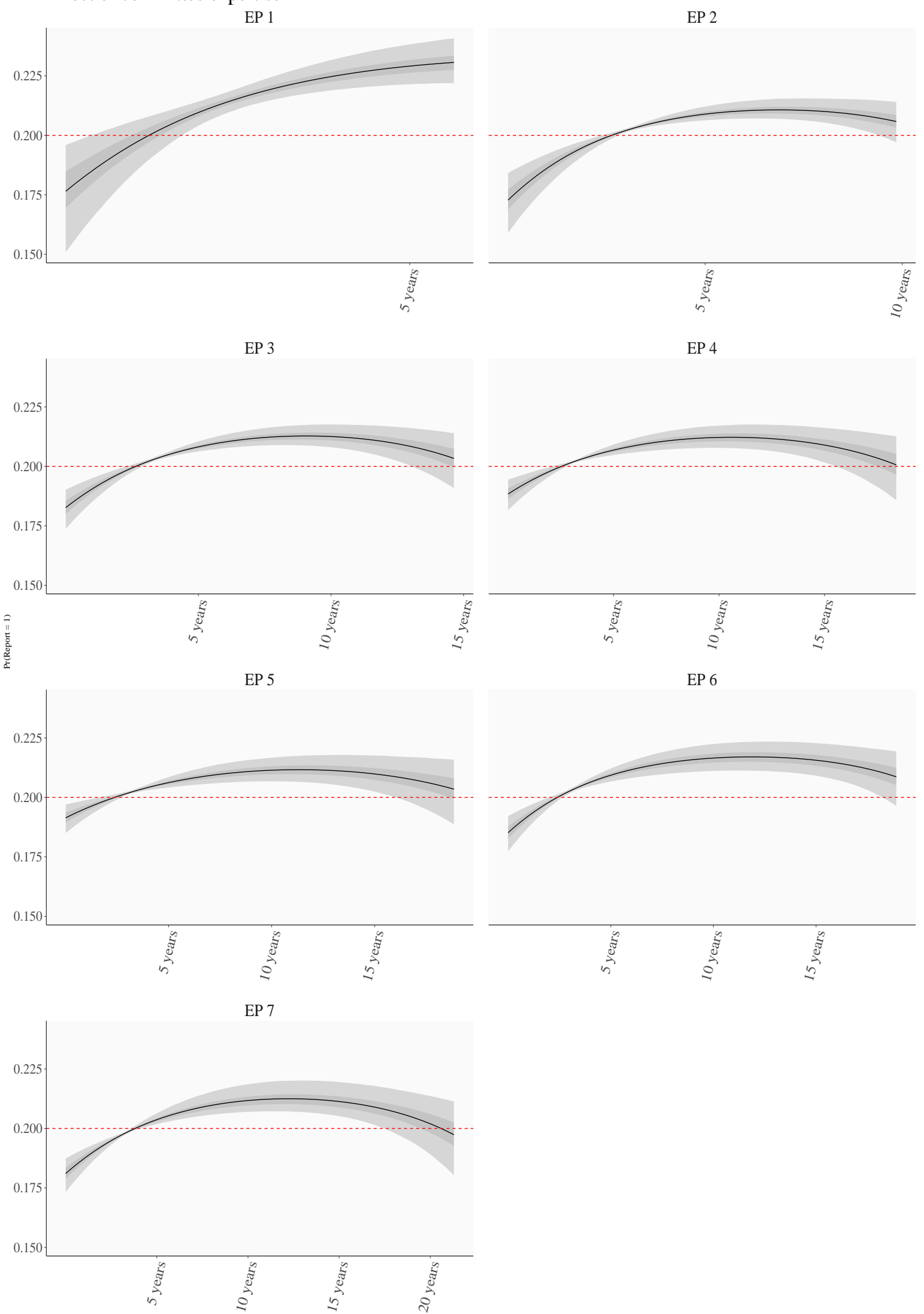

Figure 3: Substantive effect of committee expertise given loyalty across time periods.

Note: Based on Model 1g, loyalty fixed at .9. Size of choice-set is 5. Loyalty and expertise are fixed at time-period specific medians. The range of the x-axis covers the 99 percentile of committee expertise. Note that in EP 1, some MEPs have parliamentary experience from the period before the first direct elętions. Dark (50\%) and light (95\%) shaded ribbons for credible intervals. 
over time observed at the aggregate level (Hix, Noury and Roland 2007). While the overall level of loyalty is higher today than previously, coordinators nevertheless continue to select the most loyal members. This speaks to the increasing importance of party dynamics in the EP.

On the other hand, the effect of committee experience is decreasing over time. This should be seen against the gradual increase in the number of MEPs with substantive committee expertise. Coordinators, therefore, can choose between more expert members today than before so that expertise is a less discriminating factor for the coordinator. It is also clear that the effect of experience is curvilinear across all terms. Estimates for expertise and its squared term remain clearly different from zero, with expertise squared in EP 7 being the only exception. To illustrate the effects, Figure 3 shows the effect of committee expertise for MEPs with a loyalty score of .9 , in a committee delegation of five.

Overall, we find that the results are not overly heterogeneous. By and large the main pattern holds across member states, political groups, committees, procedures, and over time. Similar conclusions, also shown in Online appendix, are found when we check to what extent the results are robust to different operationalizations of loyalty, replacing committee expertise with the number of previous reports for the committee, as well as changing the date for constructing the relevant choice-sets that the committee coordinators had to choose from.

\section{Conclusion}

We have shown that committee expertise matters for delegation of committee proposals within European party groups. Drawing on informational models, we hypothesize that loyalty and committee expertise should have a positive and non-monotonic effect, respectively. These hypotheses are tested on report delegation within committee group delegations in the European Parliament, for the 1979 - 2014 period. Through a range of different model specifications, we demonstrate that newcomers are initially disadvantaged. The coordinator is more likely to select a safe pair of hands, somebody with experience on the committee. However, this relationship is not monotonic. According to our estimate, 
additional expertise is clearly beneficial in a member's first and second term. Beyond that, there is no real gain from additional committee expertise. In fact, after two terms, it may become a liability rather than an asset.

The main implication of this finding is that there is a tension between expertise and policy drift within party groups. Members interested in policy making should strive to be assigned early to the committee that covers the policy area they seek to influence. Earlyand mid-career members may thus find it costly to switch committee because of reduced probability of receiving legislative drafts. From the perspective of legislative organization, the non-monotonic effect of expertise implies that members are discouraged from staying on the same committee for more than a decade, unless other benefits are offered to offset the decline.

\section{References}

Bailer, Stefanie and Tamaki Ohmura. 2018. "Exploring, Maintaining, and Disengaging The Three Phases of a Legislator's Life." Legislative Studies Quarterly 43(3):493 - 520.

Benedetto, Giacomo. 2005. "Rapporteurs as Legislative Entrepreneurs: The Dynamics of the Codecision Procedure in Europe's Parliament." Journal of European Public Policy 12(1):67-88.

Bowler, Shaun and David M. Farrell. 1995. "The Organization of the European Parliament: Committees, Specialization and Co-ordination." British Journal of Political Science 25(2):219-243.

Buchanan, William, Heinz Eulau, LeRoy C. Ferguson and John C. Wahlke. 1970. "The Legislator as Specialist." Western Political Quarterly 13:636 - 651.

Carrubba, Clifford J., Matthew Gabel, Lacey Murrah, Ryan Clough, Elizabeth Montgomery and Rebecca Schambach. 2006. "Off the Record: Unrecorded Legislative Votes, Selection Bias and Roll-Call Analysis." British Journal of Political Science 36(4):691704 .

Chiru, Mihail. forthcoming. "Loyal Soldiers or Seasoned Leaders? The Selection of Committee Chairs in the European Parliament." Journal of European Public Policy pp. 1-18.

Clapp, Charles L. 1963. The Congressman: His Work as He Sees It. Washington DC: Brooking Institution.

Costello, R. and R Thomson. 2010. "The policy impact of leadership in committees: Rapporteurs' influence on the European Parliament's opinions." European Union Politics 11(2):219 - 240 .

Crawford, Vincent P. and Joel Sobel. 1982. "Strategic information transmission." Econometrica 50(6):1431-51. 
Daniel, William T. 2013. "When the Agent Knows Better than the Principal: The Effect of Education and Seniority on European Parliament Assignment." Journal of Common Market Studies 51(5):832 - 848.

Daniel, William T and Shawna K Metzger. 2018. "Within or between jobs? Determinants of membership volatility in the European Parliament, 1979-2014." The Journal of Legislative Studies 24(1):90 - 108.

Daniel, William T. and Stefan Thierse. 2018. "Individual Determinants for the Selection of Group Coordinators in the European Parliament." JCMS: Journal of Common Market Studies 56(4):939 - 954.

Finke, Daniel. 2015. "Why do European Political groups call the roll?" Party Politics 21(5):750 - 762 .

Fischer, Paul E. and Phillip C. Stocken. 2001. "Imperfect Information and'Credible Communication." Journal of Accounting Research 39(1):119 - 134.

Gelman, Andrew, John B Carlin, Hal S Stern, David B Dunson, Aki Vehtari and Donald B Rubin. 2014. Bayesian Data Analysis. Chapman \& Hall/CRC.

Gilligan, Thomas and Keith Krehbiel. 1987. "Collective Decisionmaking and Standing Committees: An Informational Rationale for Restrictive Amendment Procedures." Journal of Law, Economics and Organization 30:287-335.

Hagemann, Sara and Bjørn Høyland. 2010. "Bicameral Politics in the European Unions." Journal of Common Market Studies 48(4):811 - 833.

Hermansen, Silje Synnøve Lyder. 2018. "(Self-)selection and expertise among decisionmakers in the European Parliament." The Journal of Legislative Studies 24(1):148-172.

Hix, Simon and Abdul Noury. 2018. "Power versus Ideology: Political Group Switching in the European Parliament." Legislative Studies Quarterly 43(4):551 - 594.

Hix, Simon, Abdul Noury and Gerald Roland. 2018. "Is there a selection bias in roll call votes? Evidence from the European Parliament." Public Choice 176(1-2):211 - 228.

Hix, Simon, Abdul Noury and Gerard Roland. 2005. "Power to the Parties: Cohesion and Competition in the European Parliament, 1979-2001." British Journal of Political Science 35(2):209-234.

Hix, Simon, Abdul Noury and Gerard Roland. 2007. Democratic Politics in the European Parliament. Cambridge: Cambridge University Press.

Hix, Simon, Amie Kreppel and Abdul Noury. 2003. "The Party System in the European Parliament: Collusive or Competitive?" Journal of Common Market Studies 41(2):309331.

Høyland, Bjørn, Indraneel Sircar and Simon Hix. 2009. "An Automated Database of the European Parliament." European Union Politics 10(1):143 - 152.

Høyland, Bjørn, Sara B. Hobolt and Simon Hix. 2019. "Career Ambitions and Legislative Participation: The Moderating Effect of Electoral Institutions." British Journal of Political Science 49(2):491 - 512. 
Huckshorn, Robert. 1965. "Decision-making Stimuli in the State Legislative Process." Western Political Quarteerly 18:164 - 185.

Hug, Simon. 2016. "Party pressure in the European Parliament." European Union Politics $17(2): 201-218$.

Hurka, Steffen and Michael Kaeding. 2012. "Report allocation in the European Parliament after eastern enlargement." Journal of European Public Policy 19(4):512-529.

Hurka, Steffen, Michael Kaeding and Lukas Obholzer. 2015. "Learning on the Job? EU Enlargement and the Assignment of (Shadow) Rapporteurships in the European Parliament." JCMS: Journal of Common Market Studies 53(6):1230-1247.

Kaeding, Michael. 2004. "Rapporteurship Allocation in the European Parliament: Information or Distribution?" European Union Politics 5(3):353-378.

Krehbiel, Keith. 1991. Information and Legislative Organization. Ann Arbor: The University of Michigan Press.

Kreppel, Amie. 2000. "Rules, Ideology and Coalition Formation in the European Parliament." European Union Politics 1(3):340-362.

Lindstädt, Rene, Jonathan B. Slapin and Ryan J Vander Wielen. 2012. "Adaptive behaviour in the European Parliament: Learning to balance competing demands." European Union Politics 13(4):465 - 486.

Luce, Robert. 1922. Legislative Procedure: Parliamentary Practices and the Course of Business in the Framing of Statutes. Boston: Houghton Mifflin.

Mamadouh, Virginie and Tapio Raunio. 2003. "The Committee System: Powers, Appointments and Report Allocation." Journal of Common Market Studies 41(2):333-351.

Martin, Shane. 2014. Committees. In Oxford Handbook of Legislative Studies, ed. Thomas Saalfeld Shane Martin and Kaare Strøm. Oxford University Press chapter Committees, pp. $352-368$.

McConachie, Lauros. 1898. Congressional Committees. New York: Thomas Y. Crowell.

McElroy, Gail. 2006. "Committee Representation in the European Parliament." European Union Politics 7(1):5 - 29.

Meserve, Stephen A., Daniel Pemstien and William T. Bernhard. 2009. "Political Ambition and Legislative Behavior in the European Parliament." Journal of Politics 71(3):1015 - 1032 .

Obholzer, Lukas, Steffen Hurka and Michael Kaeding. 2019. "Party Group Coordinators and Rapporteurs: Discretion and Agency Loss along the European Parliament's Chains of Delegation." European Union Politics 20(2):239-260.

R-3.5.1, Core. 2018. R: A Language and Environment for Statistical Computing. Vienna, Austria: R Foundation for Statistical Computing.

Ringe, Nils. 2010. Who Decides, and How? Preferences, Uncertainty, and Policy Choice in the European Parliament. New York: Oxford University Press. 
Roger, Léa and Thomas Winzen. 2015. "Party groups and committee negotiations in the European Parliament: outside attention and the anticipation of plenary conflict." Journal of European Public Policy 22(3):391 - 208.

Schneier, Edward. 1970. "The Intelligence of Congress: Information and Public Policy Patterns." Annals of the American Academy of Political and Social Science 388(1):14 -24 .

Shi, Haolun and Guosheng Yin. 2018. "Boosting conditional logit model." Journal of Choice Modelling 26(1):48 - 63 .

Stan, Development Team. 2016. "rstanarm: Bayesian applied regression modeling via Stan.".

Thierse, Stefan. 2016. "Going on record: Revisiting the logic of roll-call vote request in the European Parliament." European Union Politics 17(2):219 - 241.

Tobin, Maurice B. 1986. Hidden Power: The Seniority System and Other Customs of Congress. New York: Greenwood Press.

Whitaker, Richard. 2001. "Party Control in a Committee-Based Legislature? The Case of the European Parliament." Journal of Legislative Studies 7(4):63-88.

Whitaker, Richard. 2011. The European Parliament's Committees: National Party Influence and Legislative Empowerment. Routledge/UACES Contemporary European Studies Taylor \& Francis.

Yordanova, Nikoleta. 2009. "The Rationale behind Committee Assignment in the European Parliament: Distributive, Informational and Partisan Perspectives." European Union Politics 10(2):226-52.

Yordanova, Nikoleta. 2011a. "The European Parliament: In need of theory." European Union Politics 12(4):597 - 617.

Yordanova, Nikoleta. 2011b. "Inter-institutional Rules and Division of Power in the European Parliament: Allocation of Consultation and Co-decision Reports." West European Politics 34(1):97 - 121.

Yordanova, Nikoleta and Monika Mühlböck. 2015. "Tracing the selection bias in roll call votes: party group cohesion in the European Parliament." European Political Science Review 7(3):373 - 399.

Yoshinaka, Antoine, Gail McElroy and Shaun Bowler. 2010. "The Appointment of Rapporteurs in the European Parliaments." Legislative Studies Quarterly 35(4):457 - 486. 


\section{Online Appendix}

\section{Descriptive statistics}

Table A1 provides a summary of the descriptive statistics.

\section{Varying coefficients}

Table A2 presents the estimates from the models with varying coefficients. 

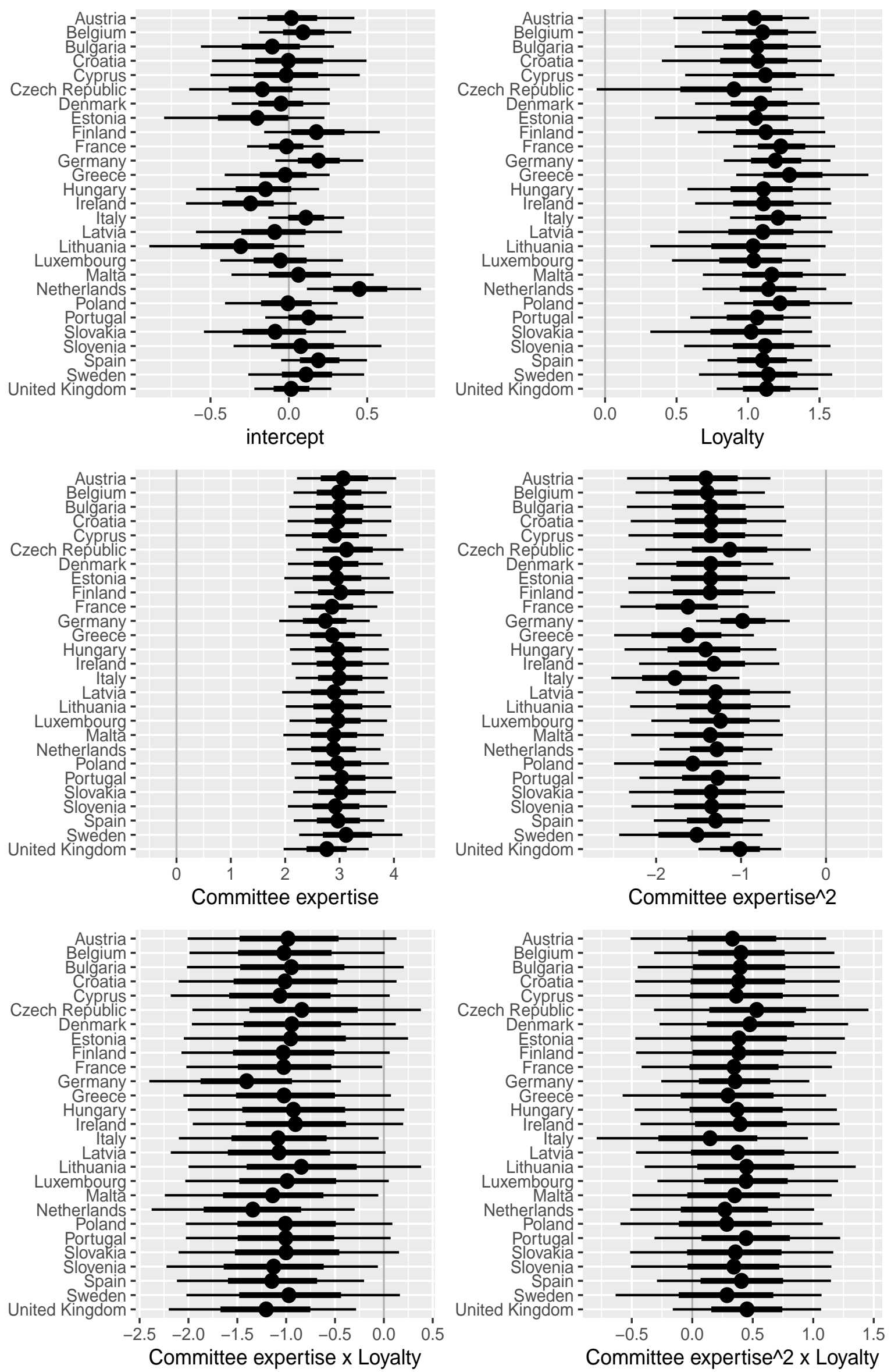

Figure A1: Results from model with varying coefficients across countries. 

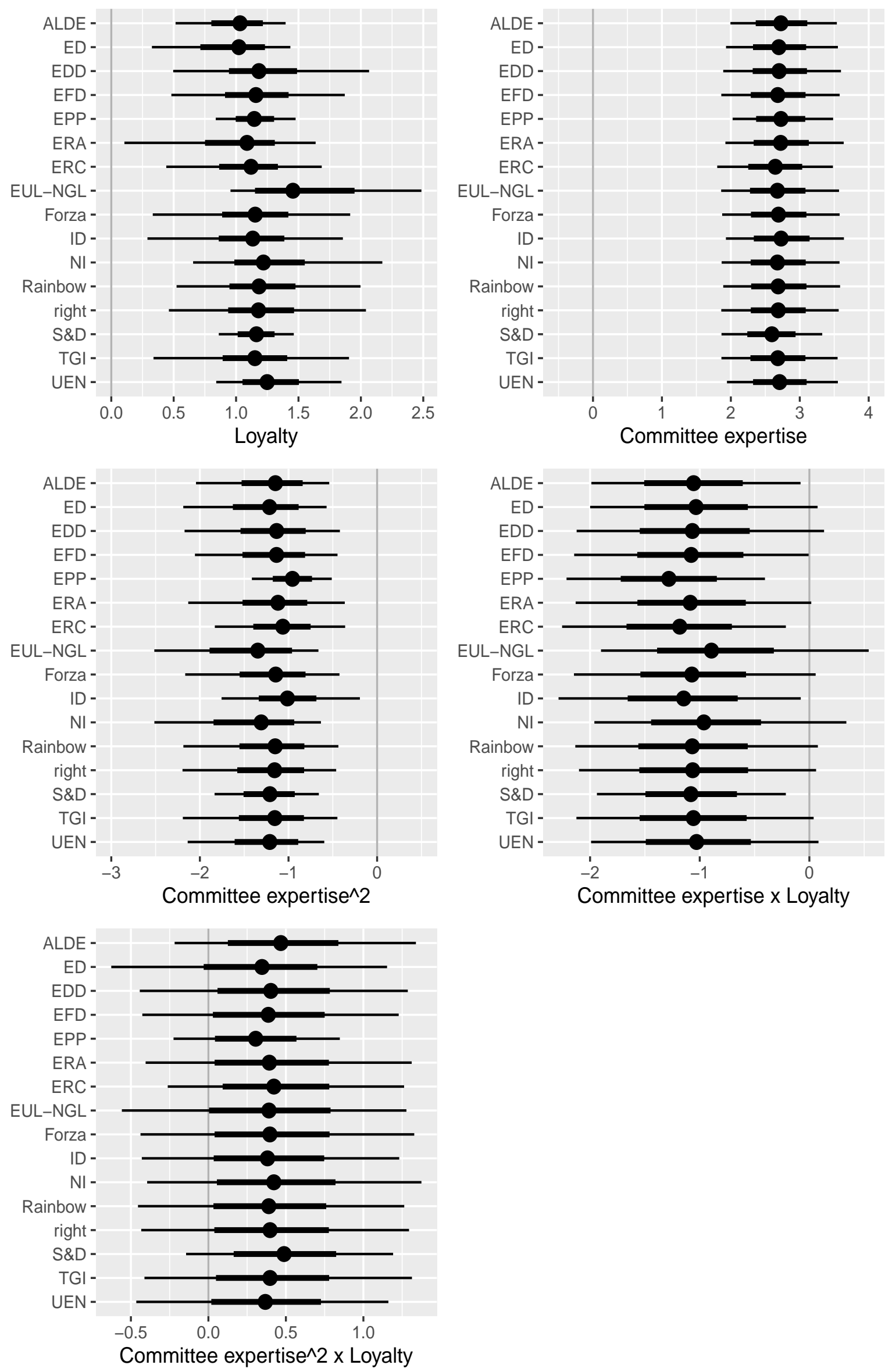

Figure A2: Results from model with varying coefficients across political groups. 

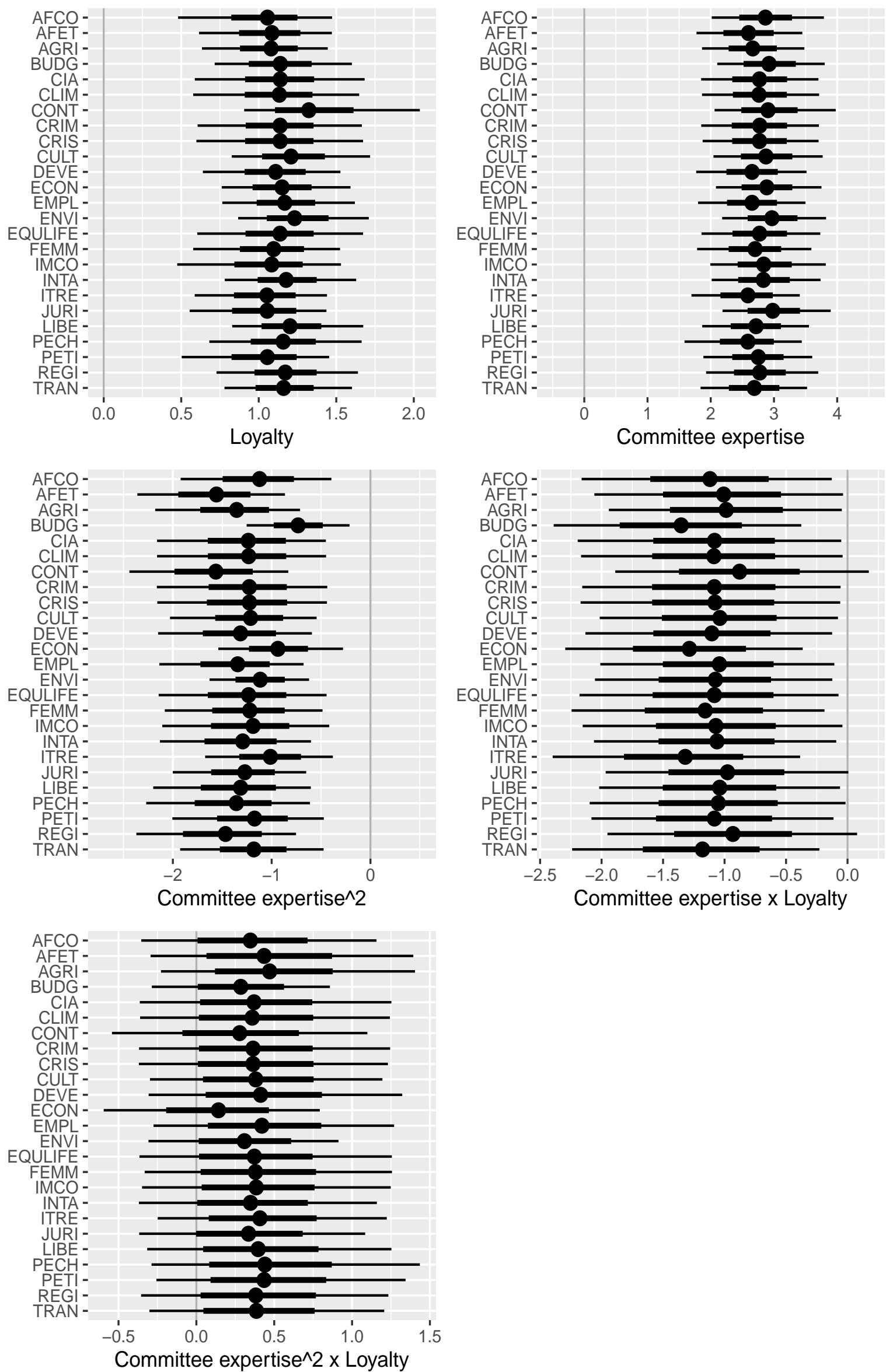

Figure A3: Results from model with varying coefficients across committees. 

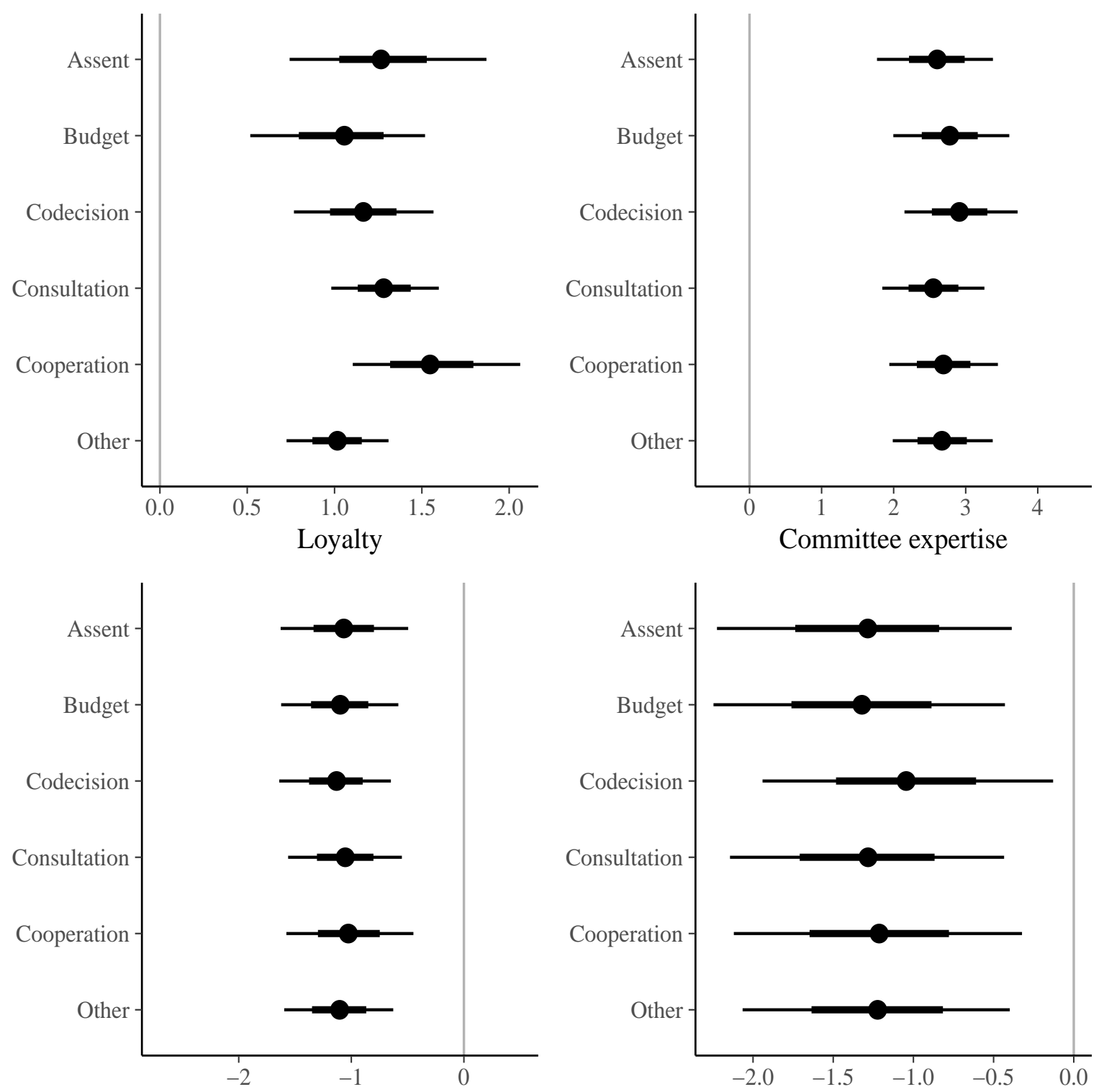

Committee expertise ${ }^{\wedge} 2$

Committee expertise $\mathrm{x}$ Loyalty

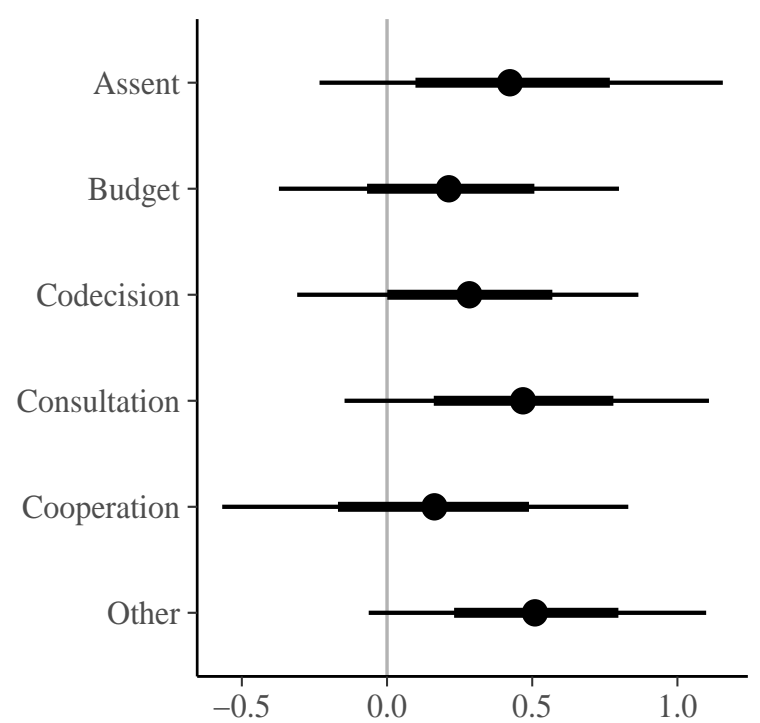

Committee expertise ${ }^{\wedge} 2 \mathrm{x}$ Loyalty

Figure A4: Results from model with varying coefficients across procedures. 

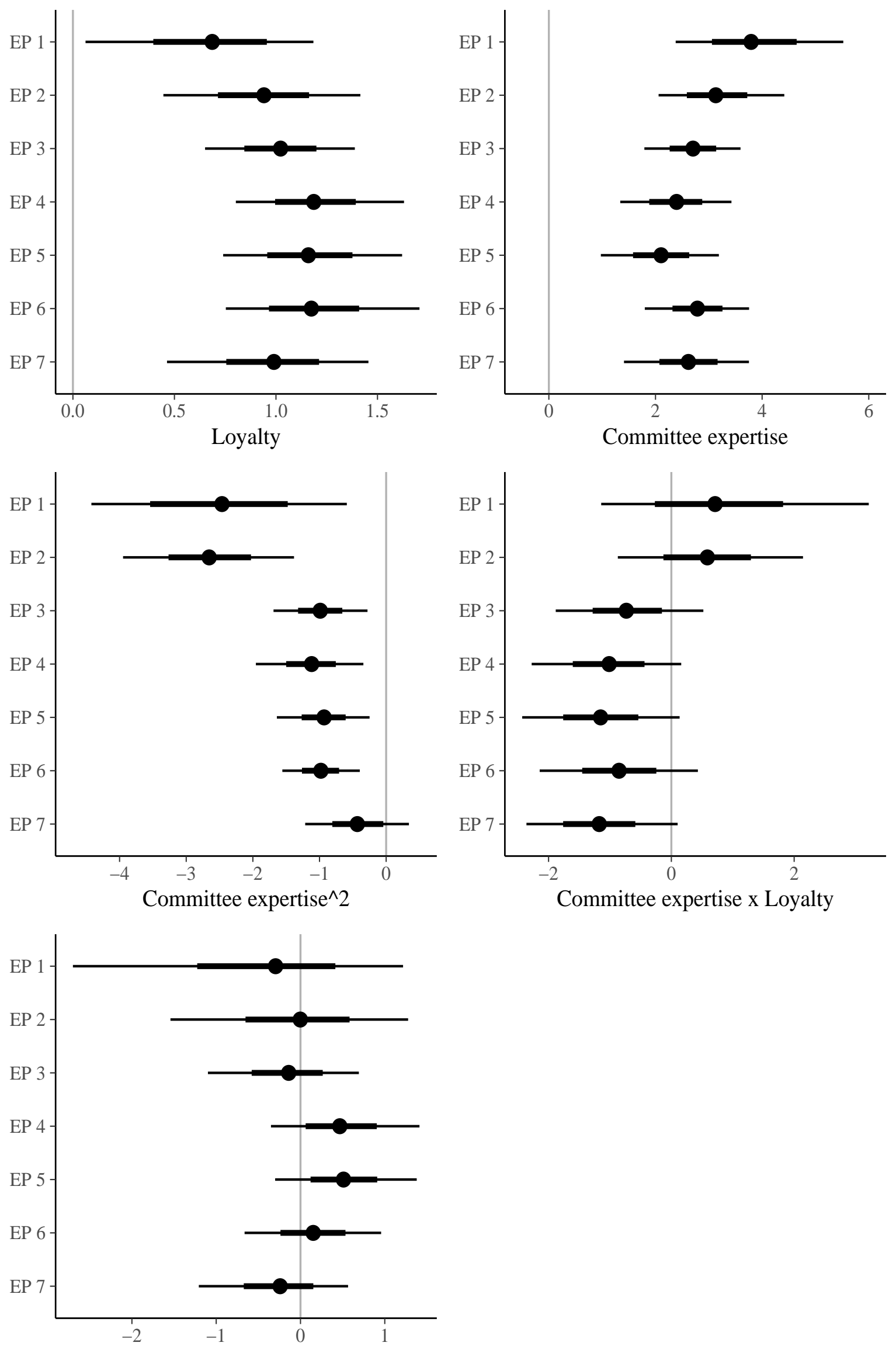

Committee expertise ${ }^{\wedge} 2 \times$ Loyalty

Figure A5: Results from model with varying coefficients over time. 


\section{Robustness checks}

\section{Robustness: Loyalty, expertise and choice-set}

In a series of robustness-checks, we re-estimate the main models by varying how we calculated loyalty, replacing committee expertise with the number of previous reports, and changing the date that formed the basis for generating the political group committee delegation from which the rapporteur is selected. In Models $2 \mathrm{a}$ and $2 \mathrm{~b}$, reported in Table A3 we calculate loyalty scores on the basis of the entire voting history of the MEPs. In Models $3 \mathrm{a}$ and $3 \mathrm{~b}$, we use votes from the last 365 days conditional on these days being in the current legislative term. In models $4 \mathrm{a}$ and $4 \mathrm{~b}$ we use only yes and no votes in the denominator (i.e., excluding abstentions) when calculating loyalty and participation. We see that the results from the main models hold up against these alternative specification of loyalty. However, we find that the interaction effect between loyalty and committee expertise is no longer clearly different from zero when using these different time-windows for calculating loyalty.

In Models 5a and 5b, we use the number of reports previously written for the committee as our measure of committee expertise. These results are presented in table A4. Again our main results hold up.

In Models $6 \mathrm{a}$ and $6 \mathrm{~b}$, we calculated loyalty to the majority position of the national delegation of the political group, rather than the majority position of the political group. We can only calculate the majority position for national delegations with at least 3 members. Moreover, it is not meaningful to estimate conditional logit models on incomplete choice-sets. We therefore dropped all choice-sets with MEPs from national delegations with less than three members. This left us with 4941 report-allocation decisions to analyze. Note that the correlation between loyalty to national party delegation and loyalty to political group is .984. It is hence not possible to distinguish between these to set of loyalty scores in the same model.

In Models $7 \mathrm{a}$ and $7 \mathrm{~b}$, we change the date of the allocation decision to 90 days before the vote. This is to guard against post-treatment bias in the loyalty estimate. In other words, we want to guard against the possibility that MEPs become more loyalty because they are allocated a report, rather than because loyalty in votes makes MEPs more likely to be appointed as rapporteur. The results from these models are reported in Table A5. The results are not sensitive to these changes.

It is worth noting that across all of the different model specification there is strong support for the effect of loyalty, committee expertise and committee expertise squared. The empirical support for a negative interaction effect between loyalty and committee expertise is weak.

In Models $6 \mathrm{a}$ and $6 \mathrm{~b}$, we calculated loyalty to the majority position of the national delegation of the political group, rather than the majority position of the political group. We can only calculate the majority position for national delegations with at least 3 members. Moreover, it is not meaningful to estimate conditional logit models on incomplete choice-sets. We therefore dropped all choice-sets with MEPs from national delegations with less than three members. This left us with 4941 report-allocation decisions to analyze. Note that the correlation in between loyalty to national party delegation and loyalty to political group is .984. It is hence not possible to distinguish between these to set of loyalty scores in the same model.

In Models $7 \mathrm{a}$ and $7 \mathrm{~b}$, we change the date of the allocation decision to 90 days before the vote. This is to guard against post-treatment bias in the loyalty estimate. In other 
words, we want to guard against the possibility that MEPs become more loyalty because they are allocated a report, rather than what we argue, that loyalty in votes make MEPs more likely to be appointed as rapporteur. The results from these models are reported in Table A5.

These changes do not matter for the key results. Loyalty, whether measured to national party delegation or supranational group, remains a strong predictor for report allocation. Also, changing the date for the configuration of the choice-sets does not change the results much. 
Table 1: Hierarchical conditional logit models.

Note: Committee specific MEP intercepts nested in countries. Bayesian standard errors in parentheses

\begin{tabular}{|c|c|c|}
\hline Models & $\begin{array}{r}1 \mathbf{a} \\
\beta\end{array}$ & $\begin{aligned} 1 \mathrm{~b} \\
\beta\end{aligned}$ \\
\hline Loyalty & $\begin{array}{l}1.137 \\
(.125)\end{array}$ & $\begin{array}{l}1.034 \\
(.132)\end{array}$ \\
\hline Committee Expertise & $\begin{array}{l}2.565 \\
(.330)\end{array}$ & $\begin{array}{l}2.764 \\
(.356)\end{array}$ \\
\hline Committee Expertise $^{2}$ & $\begin{array}{r}-.972 \\
(.229)\end{array}$ & $\begin{array}{r}-.930 \\
(.233)\end{array}$ \\
\hline Loyalty $\times$ Expertise & $\begin{array}{r}-1.064 \\
(.404)\end{array}$ & $\begin{array}{r}-1.130 \\
(.427)\end{array}$ \\
\hline Loyalty $\times$ Expertise $^{2}$ & $\begin{array}{r}.277 \\
(.268)\end{array}$ & $\begin{array}{r}.287 \\
(.278)\end{array}$ \\
\hline EP Seniority & & $\begin{array}{r}-.196 \\
(.119)\end{array}$ \\
\hline EP Seniority ${ }^{2}$ & & $\begin{array}{r}-.007 \\
(.053)\end{array}$ \\
\hline Participation & & $\begin{array}{r}.246 \\
(.121)\end{array}$ \\
\hline Age & & $\begin{array}{r}.045 \\
(.015)\end{array}$ \\
\hline $\mathrm{Age}^{2}$ & & $\begin{array}{l}-.001 \\
(.000)\end{array}$ \\
\hline Political Group Leader & & $\begin{array}{r}.103 \\
(.036)\end{array}$ \\
\hline Committee Leader & & $\begin{array}{r}.725 \\
(.038)\end{array}$ \\
\hline Parliament Leader & & $\begin{array}{r}.027 \\
(.062)\end{array}$ \\
\hline Group Switcher & & $\begin{array}{r}.016 \\
(.073)\end{array}$ \\
\hline Final Year & & $\begin{array}{r}-.238 \\
(.045)\end{array}$ \\
\hline Random effects & Std. dev & Std. dev \\
\hline Committee member intercept & .824 & .762 \\
\hline Country intercept & .198 & .218 \\
\hline N. observations & 117,837 & 117,837 \\
\hline N. reports & 11,075 & 11,075 \\
\hline N. committee members & 5056 & 5056 \\
\hline N. countries & 28 & 28 \\
\hline
\end{tabular}




\begin{tabular}{lrrrrrr}
\hline & Mean & SD & Min & 25 quantile & 75 quantile & Max \\
\hline Rapporteur & 0.094 & 0.292 & 0.000 & 0.000 & 0.000 & 1.000 \\
Loyalty (current term) & 0.740 & 0.252 & 0.000 & 0.658 & 0.917 & 0.998 \\
Loyalty (last 365 days) & 0.467 & 0.191 & 0.000 & 0.385 & 0.526 & 0.998 \\
Loyalty (current and last term) & 0.721 & 0.254 & 0.000 & 0.648 & 0.893 & 0.998 \\
Committee expertise & 0.416 & 0.382 & 0.000 & 0.146 & 0.538 & 2.963 \\
EP seniority & 0.614 & 0.503 & 0.001 & 0.238 & 0.873 & 3.469 \\
Previous reports & 3.278 & 6.807 & 0.000 & 0.000 & 3.000 & 70.000 \\
Age & 53.147 & 9.784 & 21.693 & 46.616 & 60.041 & 88.778 \\
Participation in votes (current term) & 0.818 & 0.194 & 0.000 & 0.728 & 0.965 & 1.000 \\
Participation (last 365 days) & 0.820 & 0.206 & 0.000 & 0.721 & 0.980 & 1.000 \\
Participation (current and last term) & 0.816 & 0.183 & 0.000 & 0.723 & 0.958 & 1.000 \\
Group switcher & 0.079 & 0.269 & 0.000 & 0.000 & 0.000 & 1.000 \\
Final year & 0.138 & 0.345 & 0.000 & 0.000 & 0.000 & 1.000 \\
\hline
\end{tabular}

Table A1: Table of descriptive statistics.

Table A2: Models with varying coefficients.

Note: Bayesian standard errors in parentheses.

\begin{tabular}{|c|c|c|c|c|c|}
\hline Models & $\begin{array}{r}\mathbf{1 c} \\
\beta\end{array}$ & $\begin{array}{r}\mathbf{1 d} \\
\beta\end{array}$ & $\begin{array}{r}\mathbf{1 e} \\
\beta\end{array}$ & $\begin{array}{r}\mathbf{1 f} \\
\beta\end{array}$ & $\mathbf{1 g}$ \\
\hline \multirow[t]{2}{*}{ Loyalty } & 1.107 & 1.164 & 1.134 & 1.214 & 1.023 \\
\hline & $(.150)$ & $(.166)$ & $(.141)$ & $(.180)$ & $(.176)$ \\
\hline \multirow[t]{2}{*}{ Committee Expertise } & 2.967 & 2.702 & 2.776 & 2.701 & 2.794 \\
\hline & $(.379)$ & $(.371)$ & $(.363)$ & $(.365)$ & $(.496)$ \\
\hline \multirow[t]{2}{*}{ Committee Expertise $^{2}$} & -1.378 & -1.170 & -1.253 & -1.082 & -1.357 \\
\hline & $(.317)$ & $(.303)$ & $(.284)$ & $(.243)$ & $(.477)$ \\
\hline \multirow[t]{2}{*}{ Loyalty $\times$ Expertise } & -1.046 & -1.066 & -1.089 & -1.229 & -.512 \\
\hline & $(.464)$ & $(.452)$ & $(.446)$ & $(.429)$ & $(.592)$ \\
\hline \multirow[t]{2}{*}{ Loyalty $\times$ Expertise $^{2}$} & .371 & .396 & .381 & .344 & .056 \\
\hline & $(.335)$ & $(.323)$ & $(.321)$ & $(.293)$ & $(.436)$ \\
\hline \multirow[t]{2}{*}{ Random effects } & Std. dev & Std. dev & Std. dev & Std. dev & Std. dev \\
\hline & Country & Groups & Committees & Procedures & Time \\
\hline Committee member intercept & .820 & .823 & .819 & .826 & .821 \\
\hline Country intercept & .260 & .200 & .199 & .195 & .187 \\
\hline Loyalty & .221 & .324 & .225 & .311 & .353 \\
\hline Committee Expertise & .288 & .252 & .300 & .251 & .808 \\
\hline Committee Expertise $^{2}$ & .362 & .313 & .337 & .189 & .922 \\
\hline Loyalty $\times$ Expertise & .336 & .329 & .314 & .232 & .885 \\
\hline Loyalty $\times$ Expertise $^{2}$ & .254 & .285 & .250 & .266 & .644 \\
\hline N. observations & 117,837 & 117,837 & 117,837 & 117,837 & 117,837 \\
\hline N. reports & 11,075 & 11,075 & 11,075 & 11,075 & 11,075 \\
\hline N. Committee members & 5056 & 5056 & 5056 & 5056 & 5056 \\
\hline N. countries & 28 & 28 & 28 & 28 & 28 \\
\hline N. EPG & & 17 & & & \\
\hline N. Committees & & & 25 & & \\
\hline N. Procedures & & & & 6 & \\
\hline N. Legislative terms & & & & & 7 \\
\hline
\end{tabular}


Table A3: Robustness checks I

Note: Models 2a and 2b calculate loyalty and participation on the basis of all votes in all terms served until the decision. Models $3 \mathrm{a}$ and $3 \mathrm{~b}$ calculate loyalty on the basis of the last 365 days leading up to the decision. Bayesian standard errors in parentheses.

\begin{tabular}{|c|c|c|c|c|}
\hline Models & $\begin{array}{r}\mathbf{2 a} \\
\beta\end{array}$ & $\begin{array}{r}2 \mathbf{b} \\
\beta\end{array}$ & $\begin{array}{r}\mathbf{3 a} \\
\beta\end{array}$ & $\begin{array}{r}\mathbf{3 b} \\
\beta\end{array}$ \\
\hline \multirow[t]{2}{*}{ Loyalty } & 0.936 & .829 & 1.158 & 1.079 \\
\hline & $(.119)$ & $(.126)$ & $(.147)$ & $(.153)$ \\
\hline \multirow[t]{2}{*}{ Committee Expertise } & 1.765 & 1.922 & 1.654 & 1.908 \\
\hline & $(.295)$ & $(.309)$ & $(.251)$ & $(.265)$ \\
\hline \multirow[t]{2}{*}{ Committee Expertise $^{2}$} & -.479 & -.424 & -.711 & -.721 \\
\hline & $(.181)$ & $(.181)$ & $(.163)$ & $(.173)$ \\
\hline \multirow[t]{2}{*}{ Loyalty $\times$ Expertise } & .041 & -.036 & .233 & .048 \\
\hline & $(.383)$ & $(.378)$ & $(.449)$ & $(.459)$ \\
\hline \multirow{2}{*}{ Loyalty $\times$ Expertise $^{2}$} & -.403 & -.387 & -.147 & -.039 \\
\hline & $(.231)$ & $(.227)$ & $(.303)$ & $(.316)$ \\
\hline \multirow[t]{2}{*}{ EP Seniority } & & -.143 & & -.190 \\
\hline & & $(.119)$ & & $(.119)$ \\
\hline \multirow{2}{*}{ EP Seniority ${ }^{2}$} & & -.024 & & -.010 \\
\hline & & $(.054)$ & & $(.053)$ \\
\hline \multirow[t]{2}{*}{ Participation } & & .371 & & .176 \\
\hline & & $(.137)$ & & $(.109)$ \\
\hline \multirow[t]{2}{*}{ Age } & & .042 & & .045 \\
\hline & & $(.015)$ & & $(.015)$ \\
\hline \multirow[t]{2}{*}{$\mathrm{Age}^{2}$} & & -.001 & & -.001 \\
\hline & & $(.000)$ & & $(.000)$ \\
\hline \multirow[t]{2}{*}{ Political Group Leader } & & .109 & & .095 \\
\hline & & $(.037)$ & & $(.036)$ \\
\hline \multirow[t]{2}{*}{ Committee Leader } & & .724 & & .725 \\
\hline & & $(.038)$ & & $(.037)$ \\
\hline \multirow[t]{2}{*}{ Parliament Leader } & & .024 & & .031 \\
\hline & & $(.065)$ & & $(.063)$ \\
\hline \multirow[t]{2}{*}{ Group Switcher } & & .108 & & -.099 \\
\hline & & $(.077)$ & & $(.071)$ \\
\hline \multirow[t]{2}{*}{ Final Year } & & -.238 & & -.235 \\
\hline & & $(.045)$ & & $(.045)$ \\
\hline Random effects & Std. dev & Std. dev & Std. dev & Std. dev \\
\hline Committee member intercept & .826 & .762 & .825 & .762 \\
\hline Country intercept & .194 & .211 & .206 & .225 \\
\hline N. observations & 117,837 & 117,837 & 117,837 & 117,837 \\
\hline N. reports & 11,075 & 11,075 & 11,075 & 11,075 \\
\hline N. Committee members & 5056 & 5056 & 5056 & 5056 \\
\hline N. countries & 28 & 28 & 28 & 28 \\
\hline
\end{tabular}


Table A4: Robustness checks II

Models $4 \mathrm{a}$ and $4 \mathrm{~b}$ calculate loyalty and participation using yes and no votes only, excluding abstentions. Models 5a and 5b use previous reports written in the committee as a measure of committee expertise. Bayesian standard errors in parentheses.

\begin{tabular}{|c|c|c|c|c|}
\hline Models & $\begin{array}{r}4 \mathbf{a} \\
\beta\end{array}$ & $\begin{array}{r}4 \mathbf{b} \\
\beta\end{array}$ & $\begin{array}{r}5 \mathbf{a} \\
\beta\end{array}$ & $\begin{array}{r}5 \mathrm{~b} \\
\beta\end{array}$ \\
\hline Loyalty & $\begin{array}{r}.672 \\
(.144)\end{array}$ & $\begin{array}{r}.142 \\
(.150)\end{array}$ & $\begin{array}{r}.996 \\
(.083)\end{array}$ & $\begin{array}{r}.926 \\
(.090)\end{array}$ \\
\hline Committee Expertise & $\begin{array}{r}2.656 \\
(.439)\end{array}$ & $\begin{array}{l}2.695 \\
(.448)\end{array}$ & & \\
\hline Previous Reports & & & $\begin{array}{r}.135 \\
(.014)\end{array}$ & $\begin{array}{r}.129 \\
(.014)\end{array}$ \\
\hline Committee Expertise ${ }^{2}$ & $\begin{array}{r}-0.945 \\
(.305)\end{array}$ & $\begin{array}{l}-.849 \\
(.300)\end{array}$ & & \\
\hline Previous Reports ${ }^{2}$ & & $\begin{array}{r}-.002 \\
(.000)\end{array}$ & -.002 & $(.000)$ \\
\hline Loyalty $\times$ Expertise & $\begin{array}{r}-1.048 \\
(.466)\end{array}$ & $\begin{array}{r}-.899 \\
(.479)\end{array}$ & & \\
\hline Loyalty $\times$ Previous Reports & & & $\begin{array}{r}-.082 \\
(.017)\end{array}$ & $\begin{array}{r}-.089 \\
(.019)\end{array}$ \\
\hline Loyalty $\times$ Expertise $^{2}$ & $\begin{array}{r}.206 \\
(.324)\end{array}$ & $\begin{array}{r}.153 \\
(.322)\end{array}$ & & \\
\hline Loyalty $\times$ Previous Reports ${ }^{2}$ & & & $\begin{array}{r}.001 \\
(.000)\end{array}$ & $\begin{array}{r}.001 \\
(.000)\end{array}$ \\
\hline EP Seniority & & $\begin{array}{r}-.110 \\
(.118)\end{array}$ & & $\begin{array}{r}.514 \\
(.094)\end{array}$ \\
\hline EP Seniority ${ }^{2}$ & & $\begin{array}{r}-.032 \\
(.053)\end{array}$ & & $\begin{array}{r}-.232 \\
(.042)\end{array}$ \\
\hline Participation & & $\begin{array}{l}1.232 \\
(.102)\end{array}$ & & $\begin{array}{r}.131 \\
(.114)\end{array}$ \\
\hline Age & & $\begin{array}{r}.043 \\
(.015)\end{array}$ & & $\begin{array}{r}.041 \\
(.014)\end{array}$ \\
\hline $\mathrm{Age}^{2}$ & & $\begin{array}{r}-.001 \\
(.000)\end{array}$ & & $\begin{array}{r}-.001 \\
(.000)\end{array}$ \\
\hline Political Group Leader & & $\begin{array}{r}.086 \\
(.035)\end{array}$ & & $\begin{array}{r}.082 \\
(.035)\end{array}$ \\
\hline Committee Leader & & $\begin{array}{r}.735 \\
(.037)\end{array}$ & & $\begin{array}{r}.681 \\
(.037)\end{array}$ \\
\hline Parliament Leader & & $\begin{array}{r}.020 \\
(.065)\end{array}$ & & $\begin{array}{l}-.016 \\
.060)\end{array}$ \\
\hline Group Switcher & & $\begin{array}{r}-.163 \\
(.076)\end{array}$ & & $\begin{array}{r}-.032 \\
(.069)\end{array}$ \\
\hline Final Year & & $\begin{array}{r}-.233 \\
(.045) \\
\end{array}$ & & $\begin{array}{r}-.233 \\
(.045) \\
\end{array}$ \\
\hline Random effects & Std. dev & Std. dev & Std. dev & Std. dev \\
\hline Committee member intercept & .843 & .757 & .712 & .667 \\
\hline Country intercept & .223 & .211 & .189 & .187 \\
\hline N. observations & 117,837 & 117,837 & 117,837 & 117,837 \\
\hline N. reports & 11,075 & 11,075 & 11,075 & 11,075 \\
\hline N. Committee members & 3856 & 5056 & 5056 & 5056 \\
\hline N. countries & 28 & 28 & 28 & 28 \\
\hline
\end{tabular}


Table A5: Robustness check III

Models $6 \mathrm{a}$ and $6 \mathrm{~b}$ calculate loyalty to national political group delegation. Models 7a and $7 \mathrm{~b}$ set the date for configuration of the relevant choice-set to 90 days prior to the report being presented in the plenary. Bayesian standard errors in parentheses.

\begin{tabular}{|c|c|c|c|c|}
\hline Models & $\begin{array}{r}6 \mathbf{a} \\
\beta\end{array}$ & $\begin{array}{r}\mathbf{6 b} \\
\beta\end{array}$ & $\begin{array}{r}7 \mathbf{a} \\
\beta\end{array}$ & $\begin{array}{r}7 \mathrm{~b} \\
\beta\end{array}$ \\
\hline Loyalty & & & $\begin{array}{r}.971 \\
(.111)\end{array}$ & $\begin{array}{r}.866 \\
(.121)\end{array}$ \\
\hline Loyalty (national group delegation) & $\begin{array}{l}1.203 \\
(.196)\end{array}$ & $\begin{array}{l}1.098 \\
(.203)\end{array}$ & & \\
\hline Committee Expertise & $\begin{array}{l}2.659 \\
(.602)\end{array}$ & $\begin{array}{l}2.510 \\
(.620)\end{array}$ & $\begin{array}{l}1.913 \\
(.280)\end{array}$ & $\begin{array}{l}2.075 \\
(.304)\end{array}$ \\
\hline Committee Expertise $^{2}$ & $\begin{array}{r}-1.107 \\
(.409)\end{array}$ & $\begin{array}{r}-.861 \\
(.429)\end{array}$ & $\begin{array}{r}-.683 \\
(.181)\end{array}$ & $\begin{array}{r}-.611 \\
(.193)\end{array}$ \\
\hline Loyalty $\times$ Expertise & & & $\begin{array}{r}-.547 \\
(.344)\end{array}$ & $\begin{array}{r}-.575 \\
(.351)\end{array}$ \\
\hline Loyalty (national) $\times$ Expertise & $\begin{array}{r}-.840 \\
(.718)\end{array}$ & $\begin{array}{r}-.638 \\
(.709)\end{array}$ & & \\
\hline Loyalty $\times$ Expertise $^{2}$ & & & $\begin{array}{r}.024 \\
(.219)\end{array}$ & $\begin{array}{r}.010 \\
(.227)\end{array}$ \\
\hline Loyalty (national) $\times$ Expertise $^{2}$ & $\begin{array}{r}.398 \\
(.471)\end{array}$ & $\begin{array}{r}.165 \\
(.489)\end{array}$ & & \\
\hline EP Seniority & & $\begin{array}{r}-.083 \\
(.200)\end{array}$ & & $\begin{array}{r}-.180 \\
(.117)\end{array}$ \\
\hline EP Seniority ${ }^{2}$ & & $\begin{array}{r}-.028 \\
(.096)\end{array}$ & & $\begin{array}{r}-.010 \\
(.052)\end{array}$ \\
\hline Participation & & $\begin{array}{r}.135 \\
(.198)\end{array}$ & & $\begin{array}{r}.212 \\
(.121)\end{array}$ \\
\hline Age & & $\begin{array}{r}.048 \\
(.023)\end{array}$ & & $\begin{array}{r}.042 \\
(.015)\end{array}$ \\
\hline $\mathrm{Age}^{2}$ & & $\begin{array}{r}-.001 \\
(.000)\end{array}$ & & $\begin{array}{r}.000 \\
(.000)\end{array}$ \\
\hline Political Group Leader & & $\begin{array}{r}.189 \\
(.060)\end{array}$ & & $\begin{array}{r}.098 \\
(.037)\end{array}$ \\
\hline Committee Leader & & $\begin{array}{r}.740 \\
(.060)\end{array}$ & & $\begin{array}{r}.711 \\
(.037)\end{array}$ \\
\hline Parliament Leader & & $\begin{array}{r}-.051 \\
(.096)\end{array}$ & & $\begin{array}{r}.017 \\
(.064)\end{array}$ \\
\hline Group Switcher & & $\begin{array}{r}-.145 \\
(.129)\end{array}$ & & $\begin{array}{r}-.009 \\
(.072)\end{array}$ \\
\hline Final Year & & $\begin{array}{r}-.281 \\
(.073)\end{array}$ & & $\begin{array}{r}-.333 \\
(.047)\end{array}$ \\
\hline Random effects & Std. dev & Std. dev & Std. dev & Std. dev \\
\hline Committee member intercept & .862 & .809 & .822 & .759 \\
\hline Country intercept & .142 & .182 & .206 & .228 \\
\hline N. observations & 47,947 & 47,947 & 117,069 & 117,069 \\
\hline N. reports & 4941 & 4941 & 11,066 & 11,066 \\
\hline N. Committee members & 2840 & 2840 & 5101 & 5101 \\
\hline N. countries & 27 & 27 & 28 & 28 \\
\hline
\end{tabular}

